\title{
Adefovir and Lamivudine Combination Therapy in Patients with Entecavir-Resistant Chronic Hepatitis B: Antiviral Responses and Evolution of Mutations
}

\author{
Hyung Joon Yim ${ }^{a}$ Hyun Jung Lee ${ }^{a}$ Sang Jun Suh ${ }^{a}$ Yeon Seok Seo ${ }^{b}$ \\ Chang Wook Kim ${ }^{c}$ Chang Don Lee ${ }^{c}$ Sang Hoon Park ${ }^{d}$ Myung Seok Lee ${ }^{d}$ \\ Choong Kee Park $^{\mathrm{e}}$ Hee Bok Chae ${ }^{\mathrm{f}}$ Moon Young Kim ${ }^{g}$ Soon Koo Baik ${ }^{\mathrm{g}}$ \\ Yun Soo Kim ${ }^{\mathrm{h}}$ Ju Hyun Kim ${ }^{\mathrm{h}}$ Jung II Lee ${ }^{\mathrm{i}}$ Jin Woo Lee ${ }^{\mathrm{i}}$ Sun Pyo Hong ${ }^{\mathrm{j}}$ \\ Soon Ho Um ${ }^{b}$
}

${ }^{a}$ Department of Internal Medicine, Korea University Ansan Hospital, Ansan, ${ }^{b}$ Department of Internal Medicine, Korea University Anam Hospital, Seoul, ' Department of Internal Medicine, The Catholic University of Korea Uijeongbu St. Mary's Hospital, Uijeongbu, 'Department of Internal Medicine, Hallym University Kangnam Sacred Heart Hospital, Seoul,

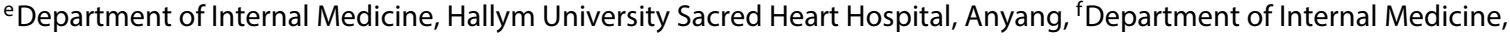
Chungbuk National University Hospital, Cheongju, ${ }^{9}$ Department of Internal Medicine, Yonsei University Wonju Severance Christian Hospital, Wonju, h Department of Internal Medicine, Gil Hospital, Gachon University of Medicine and Science, 'Department of Internal Medicine, Inha University Hospital, Incheon, and ' GeneMarix Inc., Yongin, Republic of Korea

\section{Key Words}

Adefovir - Chronic hepatitis B · Entecavir - Lamivudine · Resistance

\footnotetext{
Abstract

Objective: This study was designed to prospectively evaluate the antiviral responses and evolution of resistance mutations during adefovir (ADV) plus lamivudine (LMV) therapy in patients with entecavir (ETV)-resistant hepatitis B virus (HBV) infection. Methods: Twenty chronic hepatitis B (CHB) patients who had been receiving ETV for more than 6 months and developed virologic breakthrough due to ETV resistance were consecutively enrolled. Results: Patients received ADV plus LMV therapy for 12 months. The baseline mean serum HBV DNA level was $5.59 \pm 1.28 \log _{10} \mathrm{IU} / \mathrm{ml}$. The $\mathrm{rtT} 184 \mathrm{~L} / \mathrm{I} / \mathrm{A} / \mathrm{F}$ (50\%), rtS202G (25\%) and mixed ETV-resistant mutations (25\%) were detected at enrollment. The mean reduction in
}

serum HBV DNA levels from baseline to 12 months was $-2.3 \pm 1.06 \log _{10} \mathrm{IU} / \mathrm{ml}(\mathrm{p}<0.001)$. Seventeen patients were followed up for the full 12 months, and complete virologic response (HBV DNA $<20 \mathrm{IU} / \mathrm{ml}$ ) was observed in 4 patients (23.5\%). Among the remaining 13 patients who still had detectable HBV DNA, 7 patients showed disappearance of ETVresistant mutations or reduction of the proportion of ETVresistant mutants. An ADV- and LMV-resistant mutant (rtA181T) emerged in 2 patients (11.7\%). Conclusions: ADV plus LMV combination therapy suppresses ETV-resistant mutants in the viral population and significantly reduces serum HBV DNA levels in ETV-resistant CHB patients.

(c) 2014 S. Karger AG, Basel

Y.H.J. received research funding from Glaxo-Smith-Kline Korea and a consultancy fee from Bristol-Meyers Squibb Korea and Gilead Science Korea.

\section{KARGER}

E-Mail karger@karger.com

www.karger.com/int (c) 2014 S. Karger AG, Basel

$0300-5526 / 14 / 0575-0239 \$ 39.50 / 0$
Soon $\mathrm{Ho} \mathrm{Um}, \mathrm{MD}, \mathrm{PhD}$

Department of Internal Medicine, Korea University Anam Hospital

126-1 Anam-dong 5-ga

Seongbuk-gu, Seoul 136-705 (Republic of Korea)

E-Mail umsh@korea.ac.kr 


\section{Introduction}

Chronic hepatitis B (CHB) is a worldwide health burden, especially in Asia $[1,2]$. Several new oral antiviral agents have emerged as promising therapies for $\mathrm{CHB}$ during the last decade. Entecavir (ETV) is a potent antiviral agent which has a high genetic barrier for development of resistance $[3,4]$. ETV resistance is rare in treatment-naïve $\mathrm{CHB}$ patients [5], and long-term administration of ETV results in regression of fibrosis or even reversal of cirrhosis [6]. In this regard, recent guidelines recommend ETV as one of the preferred first-line therapies $[7,8]$. However, resistance to ETV has been reported in treatment-experienced patients; the incidence of ETV resistance increased over $50 \%$ at treatment year 5 in lamivudine (LMV)-refractory patients [5]. Therefore, optimal treatment of ETV resistance need to be investigated, but clinical data are lacking.

Considering the cross-resistance profile, adefovir (ADV) or tenofovir (TDF) are good options for managing ETV resistance [9]. However, TDF is still not available in many Asian countries. Although ADV is also effective for ETV resistance, ADV monotherapy can predispose to development of ADV resistance because ETV-resistant hepatitis B virus (HBV) retains LMV resistance as background mutations $[10,11]$. As the ADV resistance rate is reportedly as high as $18 \%$ during the first year for LMV-resistant CHB when administered alone [12], it would be more reasonable to incorporate a drug without cross-resistance to reduce the risk of ADV resistance.

A case report has described successful treatment with a combination of ADV and LMV in a patient with ETV resistance [12]. No additional data on this combination therapy are available in a larger number of patients. It is thought that ADV and LMV combination therapy would have the potential to reduce the risk of ADV resistance and achieve lasting suppression of HBV DNA in patients with ETV resistance.

During rescue therapy due to antiviral resistance, drug-resistant mutations evolve [13-15]. The proportion of preexisting mutations may be decreased, or newly developed mutations may emerge. The changes in the mutation profile may affect the outcome of the rescue therapy. Therefore, in addition to HBV DNA quantification, serial monitoring and searching for resistance-associated mutations are needed to provide more information in terms of the assessment of antiviral responses.

The aim of this study was to evaluate the antiviral responses of ADV and LMV combination therapy in pa- tients with ETV resistance. Also, we investigated the evolution of ETV-resistant mutations during the combination therapy.

\section{Patients and Methods}

Study Design

This was an investigator-initiated, multicenter, prospective, open-label, single-arm study designed to prospectively evaluate the antiviral responses of ADV $10 \mathrm{mg}$ and LMV $100 \mathrm{mg}$ combination therapy for 12 months in $\mathrm{CHB}$ patients resistant to ETV. Twenty patients were consecutively recruited from nine hospitals affiliated with seven universities between February 2010 and February 2011. Previously, we conducted a randomized controlled trial comparing the efficacy of ETV monotherapy versus ADV plus LMV combination therapy in 219 LMV-resistant CHB patients [16]. One hundred and nine patients received ETV $1 \mathrm{mg}$ for 2 years. Eighteen patients developed ETV resistance and subsequent virologic breakthrough. Sixteen of the 18 patients agreed to participate in this study (fig. 1). Additionally, 4 patients who were referred from their primary care physician for ETV resistance and met the inclusion criteria agreed to participate. Written informed consent was obtained from the 20 patients. ETV was maintained until the start of ADV and LMV combination therapy. Biochemistry, HBV DNA quantification, serology for hepatitis B e antigen ( $\mathrm{HBeAg})$ and antibody to $\mathrm{HBeAg}$ (anti-HBe) and testing for resistance-associated mutations were performed every 3 months. Prothrombin time and hematology were assessed every 6 months. Compliance to medication was monitored by a careful interview with the physicians at each visit. Any untoward medical events were recorded for safety issues. The study protocol was approved by the institutional review board at all study sites (ClinicalTrials. gov identifier: NCT 01546116). This study was conducted in accordance with the ethical principles of the Declaration of Helsinki.

\section{Inclusion and Exclusion Criteria}

Inclusion criteria were as follows: $\mathrm{HBeAg}$-positive or -negative $\mathrm{CHB}$, positive hepatitis B surface antigen (HBsAg) for more than 6 months, age over 18 years, history of treatment with ETV for more than 6 months, proven ETV-resistant mutations determined by restriction fragment mass polymorphism (RFMP) assay and an HBV DNA level over 2,000 IU/ml. All patients needed to have compensated liver disease determined by a Child-Pugh-Turcotte score $\leq 7$, prolongation of prothrombin time $\leq 3 \mathrm{~s}$, serum albumin $>3 \mathrm{~g} / \mathrm{dl}$, total bilirubin $<2.5 \mathrm{mg} / \mathrm{dl}$ and no history of variceal bleeding, ascites or hepatic encephalopathy. Only patients who were willing to give informed consent and met all the above criteria were included.

Exclusion criteria were as follows: one or more predefined laboratory abnormalities including serum phosphorous level $<2.4 \mathrm{mg} / \mathrm{dl}$, serum creatinine level $>1.5 \mathrm{mg} / \mathrm{dl}$, creatinine clearance $<50 \mathrm{ml} / \mathrm{min}$, absolute neutrophil count $<1,000$ cells $/ \mathrm{ml}$, hemoglobin level $<10 \mathrm{~g} / \mathrm{dl}$ in males and $<9 \mathrm{~g} / \mathrm{dl}$ in females or serum $\alpha$-fetoprotein $>100 \mathrm{ng} / \mathrm{ml}$, and history of treatment with interferon- $\alpha$, thymosin $\alpha 1$ or nucleos $(t)$ ide analogues other than ETV within 6 months of screening; history or evidence of ADV resistance; history of organ transplantation; positive antibody test to human immunodeficiency virus, hepatitis $\mathrm{C}$ virus or hepatitis $\mathrm{D}$ virus; pregnant or breast-feeding condition; hepatocellular car- 
Fig. 1. Flowchart of study participants. $\mathrm{RCT}=$ Randomized controlled trial; $\mathrm{Cr}=$ creatinine; $\mathrm{CBC}=$ complete blood count; INR = international normalized ratio.

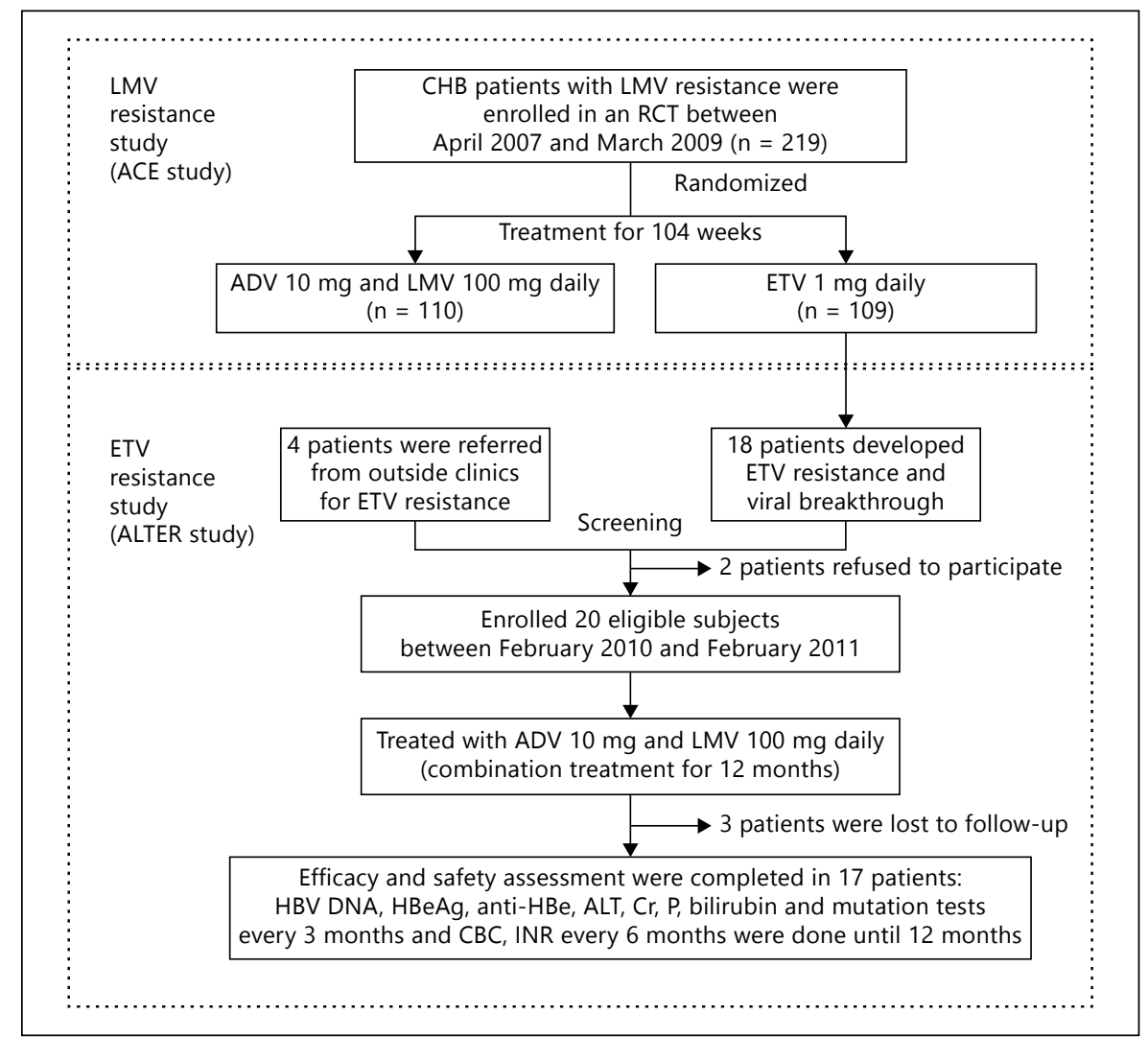

cinoma or uncontrolled malignant diseases, or habitual alcohol consumption of more than $140 \mathrm{~g}$ per week for men and $70 \mathrm{~g}$ per week for women.

\section{Endpoints of the Study}

The primary efficacy endpoint was the degree of HBV DNA reduction from baseline during the 12-month period of ADV and LMV combination therapy. The secondary efficacy endpoint was the rate of complete virologic response, which was defined as the decrease of HBV DNA to an undetectable level $(<20 \mathrm{IU} / \mathrm{ml})$ by real-time PCR assay, normalization of alanine transaminase (ALT; $\leq 45 \mathrm{IU} / \mathrm{l}), \mathrm{HBeAg}$ to anti-HBe seroconversion, development of an ADV-resistant mutation and virologic breakthrough through 12 months of treatment. The safety endpoint was the development of any adverse events. In addition, the evolution of antiviral-resistant mutations was evaluated.

\section{Assays}

Assays were performed at central laboratories (HBV DNA quantification, HBsAg, HBeAg and anti-HBe tests at Seoul Clinical Laboratory, Seoul, Korea; RFMP at Green Cross Reference Laboratory, Yongin, Korea), except for biochemical, hematologic and coagulation tests, which were performed at the local laboratories of each study site using standard methods. HBV DNA was measured by the Cobas TaqMan ${ }^{\mathrm{TM}}$ assay (Roche Diagnostics, Branchburg, N.J., USA). The lower detection limit was $20 \mathrm{IU} / \mathrm{ml}$. HBsAg, HBeAg and anti-HBe were measured by electrochemiluminescence immunoassay (Roche Diagnostics, Basel, Switzerland). Ge- notypic resistance was evaluated by an RFMP assay based on amplification and mass detection of oligonucleotides excised by restriction enzyme digestion using matrix-assisted laser desorption/ ionization time of flight mass spectrometry as previously described $[10,17,18]$. Briefly, viral DNA was extracted using a QIAamp blood kit (Qiagen, Chatsworth, Calif., USA) according to the manufacturer's instructions and amplified using primers for detection of mutations resistant to ETV [5'-GGATGCCTGGGCTTTCG CAAG-3' (nucleotides 618-633), 5'-GGATGCACTCCCA TAGG$3^{\prime}$ (nucleotides 648-637) for the rt169 codon; $5^{\prime}$-CCTCAGTCC GTTTCTCCTCTGAAGCCGGCTCAGTTT-3' (nucleotides 651676), $5^{\prime}$-TTGGCCCCCAATACCACACTGAAGTCCGGTCCAT ATA-3' (nucleotides 764-736) for the rt184 and rt202 codons; $5^{\prime}$-TTCCCCCACTGTTTGGCTGAAGTTCCGGAGTTAT-3' (nucleotides 711-738), 5'-AAAGTACCCCAACTTCCACTGAA GTTTCCGGATATCC-3' (nucleotides 908-880) for the rt204 and rt250 codons], ADV [5'-CCTATGGGAGTGGGTCCAACTCAG CGTTTCTC-3' (nucleotides 637-666), 5'-GAAAGCCAAACA GTGGGGGAAAGC-3' (nucleotides 732-709) for the rt181 codon; $5^{\prime}$-TTACCAATTTTCTTTTGTCTCCAACTGGGTAAATA TTT-3' (nucleotides 800-833), 5'-TAGCCCCAACGTTTGGTT TTATT-3' (nucleotides 863-841) for the rt236 codon] and LMV [5' - A T T C C T A T GGGA G T GGG C C T C A G T G G A T G C GTTTCTC-3' (nucleotides 634-666), 5'-ACGAACCACTGAA CAAATGGCACTAGTAAACTG-3' (nucleotides 705-673) for the rt180 codon; 5'-TTCCCCCACTGTTTGGCTGGATGTCA GTTAT-3' (nucleotides 712-738), 5'-TACAGACTTGGCCCCC AATACCACATGA-3' (nucleotides 771-744) for the rt204 co- 
don]. Nucleotide sequence positions were numbered as previously detailed [19]. The presence of mutations was assessed using matrix-assisted laser desorption/ionization time of flight mass spectrometry as described previously $[10,17,18]$. The lower detection limit of the RFMP was estimated to be $100 \mathrm{IU} / \mathrm{ml}$.

\section{Definitions}

Complete virologic response was defined as above (HBV DNA $<20 \mathrm{IU} / \mathrm{ml}$ ). Early virologic response (EVR) was defined as achievement of undetectable HBV DNA at month 3. Biochemical response was defined as ALT $\leq 45$ IU/l in both sexes. Serologic responses included $\mathrm{HBeAg}$ loss or seroconversion of HBeAg to anti-HBe. According to the previous guidelines [7], virologic breakthrough was defined as a confirmed increase in HBV DNA level of more than $1 \log _{10} \mathrm{IU} / \mathrm{ml}$ (10-fold) compared to the nadir HBV DNA level on treatment, biochemical breakthrough as an increase in ALT above the upper limit of normal after achieving normalization during continued treatment, and genotypic resistance as detection of mutations that have been shown in in vitro studies to confer resistance to the nucleos(t)ide analogues being administered. Primary nonresponse was defined as $<1 \log _{10} \mathrm{IU} / \mathrm{ml}$ decrease in HBV DNA level from the baseline at 3 months of treatment [7].

\section{Statistical Analyses}

Statistical analyses were performed using SPSS version 12.0 (SPSS, Chicago, Ill., USA). For the evaluation of the antiviral efficacy through the 12 months of the treatment period, repeatedmeasurement analysis of variance (ANOVA) was performed, and post hoc analysis was done with the Bonferroni test to compare the HBV DNA level between baseline and months 3, 6, 9 and 12. Univariate and multivariate logistic regression analysis was performed for the factors associated with complete virologic response. Serum HBV DNA levels were compared after converting to a logarithmic scale. A p value $<0.05$ was considered significant.

\section{Results}

\section{Baseline Characteristics}

Twenty patients were enrolled. All patients had a history of LMV treatment failure before the switch to ETV $1 \mathrm{mg}$ and subsequent ETV resistance during the rescue therapy. Changes in HBV DNA during the ETV therapy after LMV resistance are demonstrated with available data (fig. 2a). One patient achieved complete virologic response at month 21, but virologic breakthrough occurred. All the remaining patients were partial virologic responders to ETV. They developed ETV resistance before enrollment in the present study.

Seventeen patients were HBeAg positive (85\%). Seven patients had cirrhosis (35\%). The baseline mean serum HBV DNA level was $5.59 \pm 1.28 \log _{10} \mathrm{IU} / \mathrm{ml}$ (median 5.66, range 3.36-7.45). Seven patients (35\%) had HBV DNA less than $5 \log _{10} \mathrm{IU} / \mathrm{ml}$; in 5 patients $(25 \%)$ it was between
5 and $6 \log _{10} \mathrm{IU} / \mathrm{ml}$, and in 8 patients (40\%) it was over $6 \log _{10} \mathrm{IU} / \mathrm{ml}$ at baseline (fig. 2b). Resistance-associated mutations were evaluated. All the ETV resistance mutations had background LMV resistance mutations, of which the rtM204V $+\mathrm{rtL} 180 \mathrm{M}$ mutation was the most common (85\%). The rtT184L/I/A/F mutation was the most common ETV resistance mutation (50\%), followed by the rtS202G mutation (25\%), rtT184I + S202G mutation $(15 \%)$ and $\mathrm{rtI} 169 \mathrm{~T}+\mathrm{rtT} 184 \mathrm{~L} \pm \mathrm{rtM} 250 \mathrm{~V}$ mutation (10\%; table 1). No ADV-resistant mutations (rtA181V/T or $\mathrm{rtN} 236 \mathrm{~T}$ ) were detected at baseline. Forty percent of patients had elevated ALT ( $>45 \mathrm{IU} / \mathrm{l})$. ALT was higher in patients with a higher HBV DNA level, and there was a significant correlation between the baseline HBV DNA level and the ALT level $(\rho=0.519, p=0.019)$. Seventeen patients completed the 12-month follow-up.

\section{Responses to Therapy}

Virologic Responses

Mean HBV DNA levels at baseline and 3, 6, 9 and 12 months were $5.59 \pm 1.28,3.49 \pm 1.51,3.44 \pm 1.57,3.33 \pm$ 1.57 and $3.19 \pm 1.40 \log _{10} \mathrm{IU} / \mathrm{ml}$, respectively (fig. $2 \mathrm{~b}$ ). The mean reductions in serum HBV DNA levels from baseline to $3,6,9$ and 12 months were $-2.10 \pm 1.28$, $-2.14 \pm 1.43,-2.15 \pm 1.32$ and $-2.37 \pm 1.06 \log _{10} \mathrm{IU} / \mathrm{ml}$, respectively. Repeated-measurement ANOVA showed a significant reduction in HBV DNA level from baseline throughout 12 months of ADV plus LMV combination therapy $(\mathrm{p}<0.001)$. Post hoc analysis showed a significant difference in HBV DNA level between baseline and each follow-up visit (all $\mathrm{p}<0.001$ ). At month 12 , complete virologic response was observed in 4 patients ( $23.5 \%$ by per-protocol analysis, $20 \%$ by intention-totreat analysis).

\section{Biochemical and Serologic Responses}

After initiation of ADV and LMV combination therapy, serum ALT levels were gradually stabilized up to $94.4 \%$ by 9 months. Thereafter, the rate decreased to 82.4\%. Three patients lost HBeAg (21.4\%), but no patient achieved HBeAg to anti-HBe seroconversion (table 2).

\section{Antiviral Resistance}

\section{Primary Nonresponse}

Primary nonresponse, which was determined at 3 months of rescue therapy, was observed in 2 patients (10.5\%). One patient was lost to follow-up at month 12, and the other patient did not achieve complete virologic response. The former had the rtL180M + rtM204V + $\mathrm{rtT} 184 \mathrm{~T} / \mathrm{I}+\mathrm{rtS} 202 \mathrm{G}$ mutation and the latter patient had 
Fig. 2. Serum HBV DNA levels during the two treatment periods. a Changes in $\mathrm{HBV}$ DNA levels before enrollment in the present study. Patients were receiving ETV 1.0 mg due to LMV resistance. Available data from 16 patients are shown. Virologic breakthroughs were observed at 12 months of ETV therapy or later. Patients were enrolled into the present study after genotypic resistance was confirmed. b Changes in HBV DNA after enrollment in the study. Patients received a combination of ADV 10 $\mathrm{mg}$ and LMV $100 \mathrm{mg}$ due to ETV resistance. Mean serum HBV DNA levels at baseline and 3, 6, 9 and 12 months were $5.59,3.49,3.44,3.33$ and $3.19 \log _{10} \mathrm{IU} / \mathrm{ml}$, respectively. There was a significant reduction in HBV DNA from baseline to 12 months $(\mathrm{p}<0.001$, repeated-measurement ANOVA). Subject identification numbers are shown on the right of each graph.

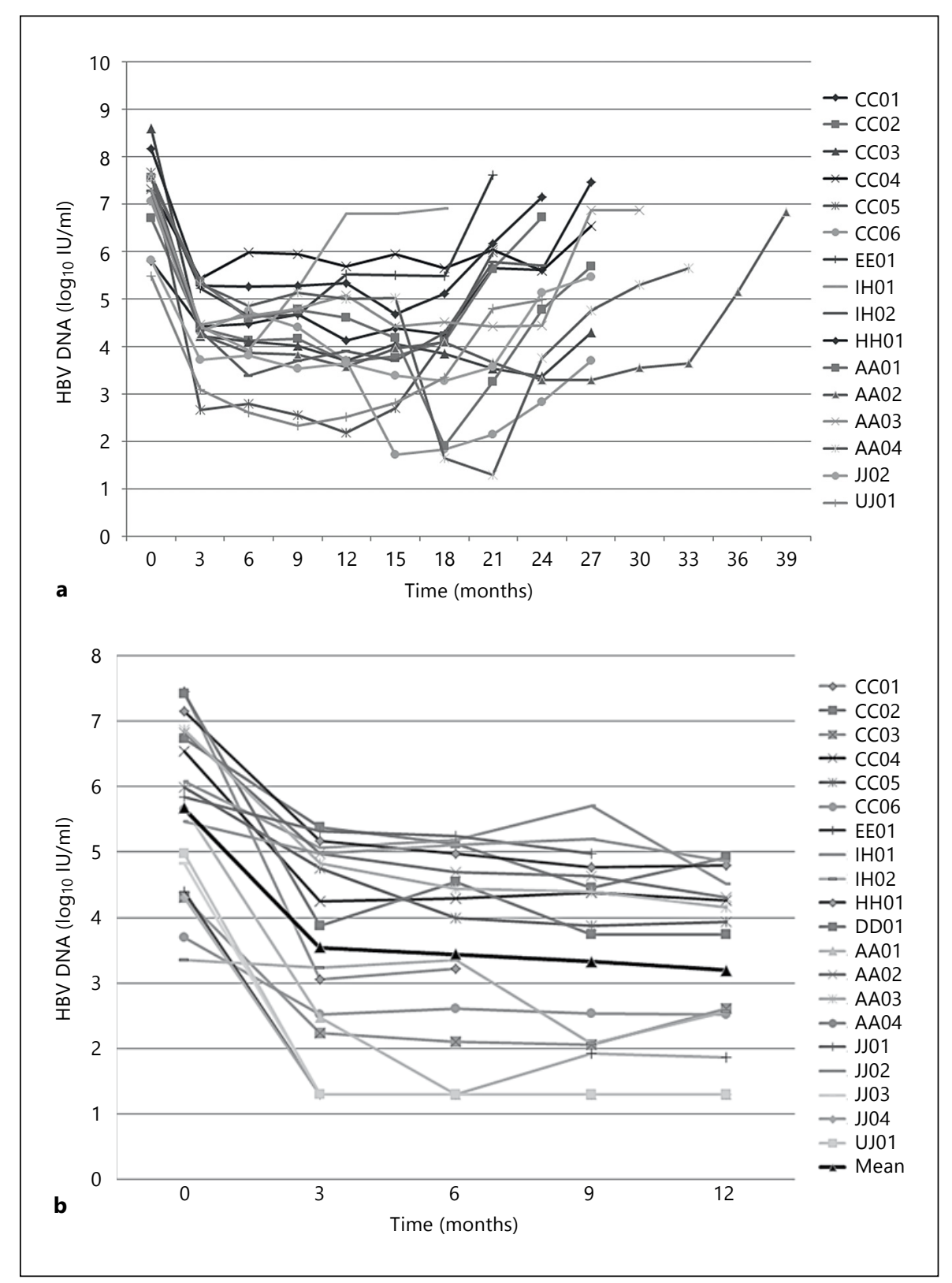

the rtL180M + rtM204V + rtS202G mutation at baseline. The mutational patterns did not change during ADV and LMV combination therapy. Also, there was no new development of any mutation associated with ADV resistance until the end of follow-up.

\section{Antiviral Resistance during Treatment}

A search for resistance-associated mutations to LMV, ADV and ETV was performed every 3 months to detect the emergence of $\mathrm{ADV}$ resistance and to monitor changes in the preexisting mutational pattern. RFMP as- say revealed genotypic resistance to ADV ( $\mathrm{rtA181T}$ ) in 2 out of 17 patients $(11.7 \%)$ by month 12 . One patient developed rtA181T at month 3 (rt181A:rt181T = 1:1), and the other patient developed the same mutation at month 9 (rt181A:rt181T = 9:1). The proportion of mutants was not high. Virologic breakthrough did not develop in either patient, and HBV DNA continued to decrease.

LMV resistance mutations continued to be detected in all patients. The mutational pattern changed during treatment in 4 patients, from rt $180 \mathrm{M}+\mathrm{rt} 204 \mathrm{~V}$ to $\mathrm{rt} 180 \mathrm{M} / \mathrm{L}+$ 
Table 1. Baseline characteristics of the patients

\begin{tabular}{lc}
\hline Parameter & \\
\hline Age, years & $47(29-74)$ \\
Male, $\mathrm{n}$ & $15(75)$ \\
HBeAg-positive, $\mathrm{n}$ & $17(85)$ \\
AST, IU/l & $31(17-72)$ \\
ALT, IU/l & $39(11-185)$ \\
HBV DNA, log 10 IU/ml & $5.66(3.36-7.45)$ \\
Duration of ETV treatment, months & $31(12-39)$ \\
Cirrhosis, $\mathrm{n}$ & $7(35)$ \\
LMV-resistant mutation, $\mathrm{n}$ & \\
M204V + L180M & $17(85)$ \\
M204V/I + L180M & $1(5)$ \\
M204I & $2(10)$ \\
ETV-resistant mutation, $\mathrm{n}$ & $11(50)$ \\
T184L/I/A/F & $5(25)$ \\
S202G & $3(15)$ \\
T184I + S202G & $1(5)$ \\
T184L + I169T & $1(5)$ \\
T184L + I169T + M250V &
\end{tabular}

Data are given as the median (range) or number (percentage) of patients. AST = Aspartate aminotransferase.

$\mathrm{rt} 204 \mathrm{~V} / \mathrm{I}$ in 2 , from $\mathrm{rt180M}+\mathrm{rt} 204 \mathrm{~V}$ to $\mathrm{rt} 180 \mathrm{M} / \mathrm{L}+$ $\mathrm{rt} 204 \mathrm{M} / \mathrm{V}$ in 1 , and from rt204I to rt204I/V in 1. Two patients developed the rtA181T mutation.

Among the 17 patients who completed follow-up, 13 patients had detectable HBV DNA at month 12 . The ETV-resistant mutation (rtT184F) disappeared in 1 patient, and the proportion of ETV-resistant mutations decreased in 6 patients. The remaining 6 patients did not show any changes in the mutational pattern or proportion of ETV-resistant mutations (table 3; fig. 3).

Virologic Breakthrough

No patient showed an increase in HBV DNA of more than $1 \log _{10} \mathrm{IU} / \mathrm{ml}$, although there was fluctuation of the HBV DNA level past month 6 in several patients.

\section{Factors Associated with Complete Virologic Response}

Univariate analysis showed the EVR (undetectable HBV DNA at month 3) as a single significant factor for complete virologic response at month 12 (OR 36.0, 95\% CI 1.7-757.8; $\mathrm{p}=0.021$ ). Baseline HBV DNA level, HBeAg, ALT, baseline ETV-resistant mutation types and presence of liver cirrhosis were not significant factors. EVR still remained as a significant factor for virologic response after adjusting $\mathrm{HBeAg}$ and baseline ALT (OR 43.5, 95\% CI 1.5$100.0 ; \mathrm{p}=0.028$ ) by multivariate analysis.

\section{Adverse Events}

An increase in serum creatinine above the normal range $(>1.5 \mathrm{mg} / \mathrm{dl})$ or to 1.5 times the baseline level was not noted. No significant hypophosphatemia was noted. No hepatocellular carcinoma was newly detected at the end of the study.

\section{Discussion}

ETV is a deoxyguanosine analogue with potent antiviral activity against HBV. Previous phase 3 clinical trials have shown ETV to be efficacious for the reduction of HBV DNA in the treatment of CHB patients $[3,4]$. The resistance rate was only $1.2 \%$ in treatment-naïve patients up to 5 years [5]. However, susceptibility to ETV decreases by 3.1 - to 20 -fold when rtL180M and rtM204V are present [20]. Further reduction is noted if there are additional changes at positions rt180M, rtS202 or rtM250 [20]. Therefore, the presence of LMV resistance mutations should be a high risk factor for subsequent ETV resistance, although multiple site mutations are required for the development of ETV resistance. In this context, the rate of ETV resistance is increased during long-term ETV treatment for LMV-refractory patients $[5,21]$.

ETV-resistant mutants are susceptible to ADV. Previous phenotypic analyses from isolates of ETV-treated patients with virologic rebound revealed the unchanged susceptibility to ADV compared with baseline [13,22]. However, clinical experience of ADV for the treatment of ETV-resistant CHB is limited. A case report suggested that switching to ADV monotherapy was effective [23]. However, ADV monotherapy may put a patient at high risk of $\mathrm{ADV}$ resistance, so combination therapy is certainly needed. We chose LMV as the combination drug with ADV because of the low risk of adverse events, low cost and good accessibility. In addition, another case report [13] prompted us to further evaluate the ADV plus LMV combination.

In our study, ADV plus LMV significantly reduced the HBV DNA level through 12 months compared with baseline ( $\mathrm{p}<0.001)$. HBV that retained ETV-resistant mutations became suppressed, so their proportion in sera decreased after treatment. However, the complete virologic response rate was lower than we had expected (20-23.5\% at month 12$)$. In addition, the mutation resistant to both ADV and LMV (rtA181T) was newly detected in 2 patients. Although virologic breakthrough did not develop in these patients, they would still be at 
Fig. 3. Changes in the antiviral resistance mutational pattern during treatment. The evolution of ETV-resistant (ETV-R) mutants during treatment among the study population is demonstrated. At 12 months, 4 patients had undetectable HBV DNA. Among 13 patients who had detectable HBV DNA, 1 patient showed disappearance of ETV-resistant mutants, 6 patients showed reductions in the proportion of ETV-resistant mutants among viral quasispecies and the remaining 6 patients did not show any changes in the mutational pattern or proportion of ETV-resistant mutations.

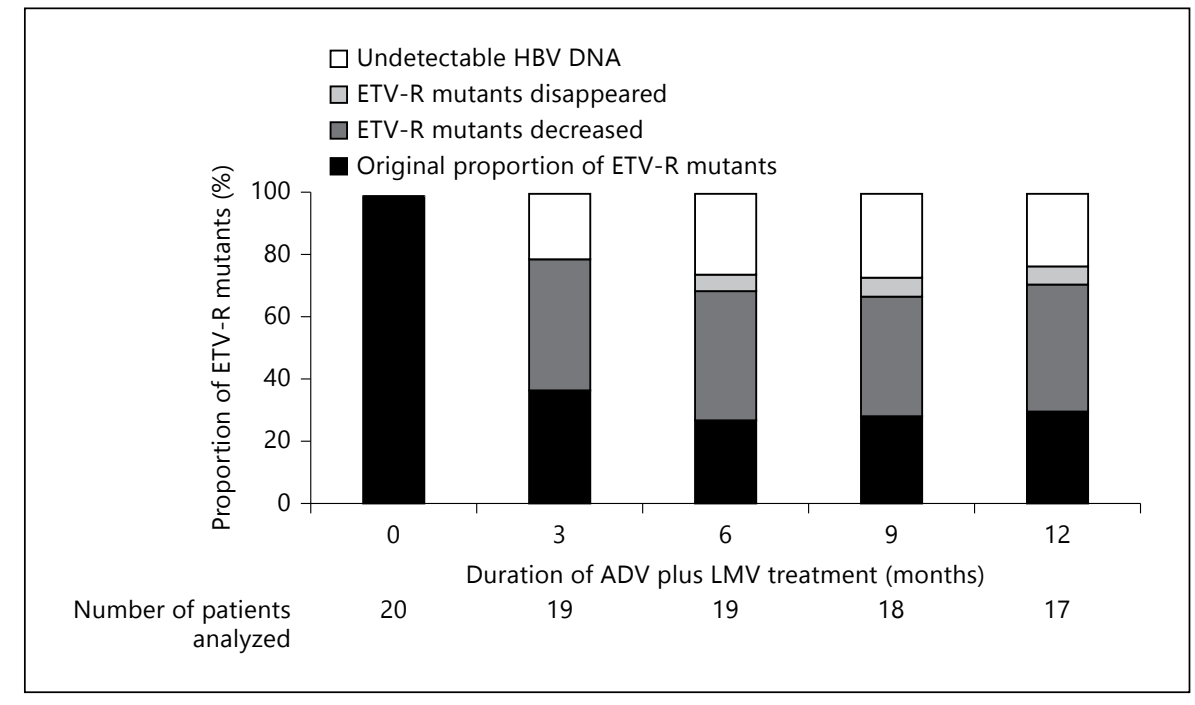

Table 2. Virologic, biochemical and serologic response to ADV and LMV combination therapy

\begin{tabular}{|c|c|c|c|c|}
\hline & 3 months & 6 months & 9 months & 12 months \\
\hline HBV DNA undetectable by PCR (<20 IU/ml), $\mathrm{n}$ & $4 / 19(21.1)$ & $5 / 19(26.3)$ & $4 / 18(22.2)$ & $4 / 17(23.5)$ \\
\hline Normal ALT, $\mathrm{n}$ & $14 / 19(73.7)$ & $16 / 19(84.2)$ & $17 / 18(94.4)$ & $14 / 17(82.4)$ \\
\hline HBeAg loss, $\mathrm{n}$ & $4 / 12(33.3)$ & $5 / 16(31.6)$ & $5 / 14(35.7)$ & $3 / 14(21.4)$ \\
\hline HBeAg seroconversion, $\mathrm{n}$ & $1 / 12(8.3)$ & $0 / 16(0)$ & $0 / 14(0)$ & $0 / 14(0)$ \\
\hline
\end{tabular}

Data are presented as the number of cases out of the number of patients being followed up (percentage in parentheses).

Table 3. Comparison of the ETV resistance mutational pattern between baseline and month 12

\begin{tabular}{|c|c|c|c|c|c|}
\hline \multirow[t]{2}{*}{ Subject No. } & \multicolumn{2}{|c|}{ Amino acid } & \multicolumn{2}{|l|}{ Ratio } & \multirow{2}{*}{$\begin{array}{l}\text { Proportion of ETV- } \\
\text { resistant mutants }\end{array}$} \\
\hline & position & wild type:mutant & baseline & month 12 & \\
\hline \multirow[t]{2}{*}{ A03 } & rt169 & Ile:Thr & $0: 1(100)$ & $2: 1(33)$ & decreased \\
\hline & $\mathrm{rt184}$ & Thr:Leu & $0: 1(100)$ & $1: 1(50)$ & decreased \\
\hline $\mathrm{C} 02$ & rt184 & Thr:Leu & $0: 1(100)$ & $0: 1(100)$ & $\mathrm{NC}$ \\
\hline \multirow[t]{2}{*}{$\mathrm{C} 05$} & $\mathrm{rt} 184$ & Thr:Ile & $5: 1(17)$ & $1: 0(0)$ & decreased \\
\hline & rt202 & Ser:Gly & $0: 1(100)$ & $1: 5(83)$ & decreased \\
\hline $\mathrm{C} 06$ & rt202 & Ser:Gly & $0: 1(100)$ & $0: 1(100)$ & $\mathrm{NC}$ \\
\hline D01 & $\mathrm{rt184}$ & Thr:Ile & $0: 1(100)$ & $0: 1(100)$ & $\mathrm{NC}$ \\
\hline E01 & rt184 & Thr:Leu & $0: 1(100)$ & $0: 1(100)$ & $\mathrm{NC}$ \\
\hline F01 & rt202 & Ser:Gly & $1: 3(75)$ & $1: 2(67)$ & decreased \\
\hline
\end{tabular}

Subjects with undetectable HBV DNA at month 12 and cases lost to follow-up were not included in this comparison. Figures in parentheses represent the percentage of mutants. $\mathrm{rt}=$ Reverse transcriptase; $\mathrm{NC}=$ no change. 
high risk of a poor response to the ADV plus LMV combination. Interestingly, the LMV-resistant mutation did not disappear in all patients, suggesting that selection pressure for the LMV-resistant mutant was being exerted. In this study, the high rate of partial virologic response to the ADV and LMV combination could be attributable to $\mathrm{HBeAg}$ positivity, $\mathrm{HBV}$ genotype $\mathrm{C}$, which is prevalent in Korea, and relatively high levels of baseline HBV DNA. The only factor associated with complete virologic response at month 12 was EVR, so an early response to this therapy is mandatory for successful treatment. Moreover, modification of the treatment strategy may be required in the absence of EVR. Another ADV combination, such as ADV plus ETV, could be an alternative therapy [24-26], but the cost will be increased. In addition, the efficacy of ADV plus ETV needs to be demonstrated compared with that of the ADV plus LMV combination because a previous retrospective study failed to show its benefit [27].

Current guidelines recommend a switch to or addition of TDF $[7,8]$. Indeed, TDF-based rescue therapy seems very effective for treating ETV-resistant or multi-drug-resistant CHB [28, 29]. However, TDF is not widely available in many Asian countries, and we were not able to prescribe TDF in Korea during the period of the present study. In the absence of TDF, ADV-based therapy could be an option for the management of ETV resistance. However, as the efficacy of ADV is limited, it would not be an optimal choice. Once TDF is available, TDF should be considered the first-line therapy for ETV resistance based on the current guidelines $[7,8]$.

In this study, we examined the changes in mutation profiles, including the proportion of each resistant mutant by RFMP. Previous RFMP results were well correlated with clonal analysis [17]. So, it would be relevant to evaluate the evolutionary change in resistant mutants with this assay. In more than half of the patients who had detectable HBV DNA at month 12, ETV-resistant mutants decreased in the proportion of viral quasispecies or disappeared. These patients tended to show a more marked decrease in the HBV DNA level than patients with no changes in the proportion of viral quasispecies (data not shown), suggesting an association of viral evolutionary changes and the replication fitness under the therapy [14].

This study has several limitations. It was a single-arm study and so could not assess superiority or inferiority compared to other treatment regimens. However, considering that a significant reduction in HBV DNA level for ETV-resistant CHB was evident, future comparative studies could be designed using our treatment regimen as a reference arm. Another limitation is the small number of study subjects. As ETV resistance is not very common in clinical practice, we were not able to enroll a large number of subjects even though we conducted a multicenter study. Future larger studies comparing ADV plus LMV with other treatment options for the treatment of ETV resistance are warranted. Lastly, the method for detection of antiviral resistance mutations could be an issue. RFMP assay cannot detect new molecular changes which may confer resistance to the given drug, although very sensitive and quantitative detection of mixed populations is possible.

However, our study has several strong points. This is the first prospective evaluation of the efficacy of ADV plus LMV for ETV-resistant CHB. There have been only case reports or small retrospective chart reviews for this combination previously; these were unable to evaluate the exact complete virologic response rate of ADV plus LMV therapy for ETV resistance. Secondly, this study was performed in a well-defined population. Past medical treatment history and characteristics were very homogeneous. All the patients received LMV first and subsequently ETV due to LMV resistance. All the patients had confirmed ETV resistance by RFMP assay at baseline. Lastly, we analyzed resistance-associated mutations regularly at 3-month intervals and observed the evolutionary changes in ETV-resistance mutants. This revealed the decreasing proportion of ETV-resistant mutants among viral quasispecies and also their disappearance in sera.

In conclusion, ADV plus LMV combination therapy significantly reduced serum HBV DNA levels in $\mathrm{CHB}$ patients with resistance to ETV although the degree of reduction was modest. ETV-resistant mutants were suppressed with the combination therapy, and the proportion of ETV-resistant mutants was decreased. However, the incidence of a resistant mutation to both ADV and LMV was not negligible.

\section{Acknowledgements}

The authors thank Dr. Eileen L. Yoon, Dr. Jeong Han Kim, Prof. Soon-Sun Kwon, Ms. Young Eun Park, Ms. Su Hyun Kim (Korea University Ansan Hospital) and clinical research coordinators at all study sites for their dedicated assistance in collecting and analyzing the data.

This study was partially supported by a grant of the Korean Healthcare Technology R\&D Project, Ministry of Health and Welfare, Republic of Korea (A 102065 to Y.H.J., S.Y.S. and U.S.H.) and partly by a research fund from Glaxo-Smith-Kline Korea. Lamivudine was kindly supplied by Glaxo-Smith-Kline Korea. 


\section{References}

$>1$ Lavanchy D: Hepatitis B virus epidemiology, 12 Lee YS, Suh DJ, Lim YS, Jung SW, Kim KM, disease burden, treatment, and current and emerging prevention and control measures. J Viral Hepat 2004;11:97-107.

$>2$ Liaw YF, Leung N, Kao JH, Piratvisuth T, Gane E, Han KH, Guan R, Lau GK, Locarnini $\mathrm{S}$ : Asian-Pacific consensus statement on the management of chronic hepatitis B: a 2008 update. Hepatol Int 2008;2:263-283.

-3 Chang TT, Gish RG, de Man R, Gadano A, Sollano J, Chao YC, Lok AS, Han KH, Goodman Z, Zhu J, Cross A, DeHertogh D, Wilber R, Colonno R, Apelian D: A comparison of entecavir and lamivudine for $\mathrm{HBeAg}$-positive chronic hepatitis B. N Engl J Med 2006;354: 1001-1010.

4 Lai CL, Shouval D, Lok AS, Chang TT, Cheinquer H, Goodman Z, DeHertogh D, Wilber R, Zink RC, Cross A, Colonno R, Fernandes L: Entecavir versus lamivudine for patients with HBeAg-negative chronic hepatitis B. N Engl J Med 2006;354:1011-1020.

$\checkmark 5$ Tenney DJ, Rose RE, Baldick CJ, Pokornowski KA, Eggers BJ, Fang J, Wichroski MJ, Xu D, Yang J, Wilber RB, Colonno RJ: Long-term monitoring shows hepatitis B virus resistance to entecavir in nucleoside-naive patients is rare through 5 years of therapy. Hepatology 2009;49:1503-1514.

-6 Chang TT, Liaw YF, Wu SS, Schiff E, Han KH, Lai CL, Safadi R, Lee SS, Halota W, Goodman Z, Chi YC, Zhang H, Hindes R, Iloeje U, Beebe $S$, Kreter B: Long-term entecavir therapy results in the reversal of fibrosis/cirrhosis and continued histological improvement in patients with chronic hepatitis B. Hepatology 2010;52:886-893

$>7$ European Association for the Study of the Liver: EASL clinical practice guidelines: management of chronic hepatitis B virus infection. J Hepatol 2012;57:167-185.

$>8$ Lok AS, McMahon BJ: Chronic hepatitis B: 19 update 2009. Hepatology 2009;50:661-662.

$>9$ Yim HJ: Management of antiviral-resistant chronic hepatitis B virus infection. Korean J Gastroenterol 2008;51:346-359.

$>10$ Yeon JE, Yoo W, Hong SP, Chang YJ, Yu SK, Kim JH, Seo YS, Chung HJ, Moon MS, Kim SO, Byun KS, Lee CH: Resistance to adefovir dipivoxil in lamivudine resistant chronic hepatitis $B$ patients treated with adefovir dipivoxil. Gut 2006;55:1488-1495.

$>11$ Tenney DJ, Levine SM, Rose RE, Walsh AW, Weinheimer SP, Discotto L, Plym M, Pokornowski K, Yu CF, Angus P, Ayres A, Bartholomeusz A, Sievert W, Thompson G, Warner N, Locarnini S, Colonno RJ: Clinical emergence of entecavir-resistant hepatitis $B$ virus requires additional substitutions in virus already resistant to lamivudine. Antimicrob Agents Chemother 2004;48:3498-3507. Lee HC, Chung YH, Lee YS, Yoo W, Kim SO: Increased risk of adefovir resistance in patients with lamivudine-resistant chronic hepatitis B after 48 weeks of adefovir dipivoxil monotherapy. Hepatology 2006;43:13851391.

13 Villet S, Ollivet A, Pichoud C, Barraud L, Villeneuve JP, Trépo C, Zoulim F: Stepwise process for the development of entecavir resistance in a chronic hepatitis B virus infected patient. J Hepatol 2007;46:531-538.

14 Yim HJ, Hussain M, Liu Y, Wong SN, Fung SK, Lok AS: Evolution of multi-drug resistant hepatitis B virus during sequential therapy. Hepatology 2006;44:703-712.

15 Kim SS, Cho SW, Kim SO, Hong SP, Cheong JY: Multidrug-resistant hepatitis B virus resulting from sequential monotherapy with lamivudine, adefovir, and entecavir: clonal evolution during lamivudine plus adefovir therapy. J Med Virol 2013;85:55-64.

16 Yim HJ, Seo YS, Yoon EL, Kim CW, Lee CD, Park SH, Lee MS, Park CK, Chae HB, Kim MY, Baik SK, Kim YS, Kim JH, Lee JI, Lee JW, Hong SP, Um SH: Adding adefovir vs. switching to entecavir for lamivudine-resistant chronic hepatitis B (ACE study): a 2-year follow-up randomized controlled trial. Liver Int 2013;33:244-254.

17 Han KH, Hong SP, Choi SH, Shin SK, Cho SW, Ahn SH, Hahn JS, Kim SO: Comparison of multiplex restriction fragment mass polymorphism and sequencing analyses for detecting entecavir resistance in chronic hepatitis B. Antivir Ther 2011;16:77-87.

$>18$ Lee CH, Kim SO, Byun KS, Moon MS, Kim EO, Yeon JE, Yoo W, Hong SP: Predominance of hepatitis B virus YMDD mutants is prognostic of viral DNA breakthrough. Gastroenterology 2006;130:1144-1152.

9 Ono Y, Onda H, Sasada R, Igarashi K, Sugino Y, Nishioka K: The complete nucleotide sequences of the cloned hepatitis B virus DNA; subtype adr and adw. Nucleic Acids Res 1983; 11:1747-1757.

20 Baldick CJ, Eggers BJ, Fang J, Levine SM, Pokornowski KA, Rose RE, Yu CF, Tenney DJ, Colonno RJ: Hepatitis B virus quasispecies susceptibility to entecavir confirms the relationship between genotypic resistance and patient virologic response. J Hepatol 2008;48: 895-902.
21 Sherman M, Yurdaydin C, Simsek H, Silva M, Liaw YF, Rustgi VK, Sette H, Tsai N, Tenney DJ, Vaughan J, Kreter B, Hindes R: Entecavir therapy for lamivudine-refractory chronic hepatitis B: improved virologic, biochemical, and serology outcomes through 96 weeks. Hepatology 2008;48:99-108.

22 Tenney DJ, Rose RE, Baldick CJ, Levine SM, Pokornowski KA, Walsh AW, Fang J, Yu CF, Zhang S, Mazzucco CE, Eggers B, Hsu M, Plym MJ, Poundstone P, Yang J, Colonno RJ: Two-year assessment of entecavir resistance in lamivudine-refractory hepatitis B virus patients reveals different clinical outcomes depending on the resistance substitutions present. Antimicrob Agents Chemother 2007;51: 902-911.

23 Yatsuji H, Hiraga N, Mori N, Hatakeyama T, Tsuge M, Imamura M, Takahashi S, Fujimoto Y, Ochi H, Abe H, Maekawa T, Suzuki F, Kumada $\mathrm{H}$, Chayama K: Successful treatment of an entecavir-resistant hepatitis B virus variant. J Med Virol 2007;79:1811-1817.

24 Chae HB, Kim MJ, Seo EG, Choi YH, Lee HS, Han JH, Yoon SM, Park SM, Youn SJ: High efficacy of adefovir and entecavir combination therapy in patients with nucleoside-refractory hepatitis B. Korean J Hepatol 2012; 18:75-83.

25 Yang HJ, Lee JH, Kim YJ, Yoon JH, Lee HS: Antiviral efficacy of combination therapy with entecavir and adefovir for entecavir/lamivudine-resistant hepatitis $B$ virus with or without adefovir resistance. J Med Virol 2012; 84:424-430.

26 Jeon JW, Shin HP, Lee JI, Joo KR, Cha JM, Park JJ, Lim JU, Lim K, Kim S: Efficacy of entecavir and adefovir combination therapy for patients with lamivudine- and entecavir-resistant chronic hepatitis B. Dig Dis Sci 2012; 57:1358-1365.

27 Kim SS, Cheong JY, Lee D, Lee MH, Hong SP, Kim SO, Cho SW: Adefovir-based combination therapy with entecavir or lamivudine for patients with entecavir-refractory chronic hepatitis B. J Med Virol 2012;84:18-25.

28 Petersen J, Ratziu V, Buti M, Janssen HL, Brown A, Lampertico P, Schollmeyer J, Zoulim F, Wedemeyer H, Sterneck M, Berg T, Sarrazin C, Lutgehetmann M, Buggisch P: Entecavir plus tenofovir combination as rescue therapy in pre-treated chronic hepatitis B patients: an international multicenter cohort study. J Hepatol 2012;56:520-526.

-29 Scotto G, D’Addiego G, Giammario A, Campanale F, Fazio V: Tenofovir plus entecavir as rescue therapy for multidrug-resistant chronic hepatitis B. Liver Int 2012;32:171-172.
Adefovir and Lamivudine for Entecavir Resistance
Intervirology 2014;57:239-247 DOI: $10.1159 / 000360399$ 